\title{
The Exploration on Innovative Teaching Mode for Graduates Who Major in Software Engineering
}

\author{
HU Jun ${ }^{1, a}$, LIU Bocheng ${ }^{1, b, *}$, CHEN Ai ${ }^{1, c}$ \\ ${ }^{1}$ School of Software, Nanchang University, Nanchang, Jiangxi, China \\ ahujun@ncu.edu.cn, bjsjjcjx@163.com, ${ }^{\text {Clisa6606@126.com }}$
}

Keywords: Innovated learning; Teaching mode;Software engineering;Master.

\begin{abstract}
Innovative education is an important topic during the process of talent training in the era of higher education. It is a direction of graduate's education innovation to cultivate the innovative and high-quality talents. In this paper, aiming at cultivating MS Software Engineering, the authors combine with practical curriculum of software engineering, explore the innovative learning and teaching mode of graduates, and achieve good results.
\end{abstract}

\section{Introduction}

With the rapid development of global knowledge economy and new propose of building an internationally competitive and innovative national goals, universities need to develop innovative education, and promote innovative learning to cultivate innovative talents. Graduate students are regarded as the backbone of the future era of knowledge economy, whose innovative abilities are not only related to the level of knowledge innovation of higher education institutions, but also related to the future of the country's overall innovation capability. Therefore, it is necessary to strengthen the innovation capacity of postgraduate training in an important position.

Innovative learning is different from independent learning, research study and creative learning. These three learning styles, which are more suitable for primary, secondary and undergraduate studies, emphasize learning of existing knowledge on creativity digestion. Besides, innovative learning requires students not to learn knowledge only from books during the study process, and not to blindly believe in the authority. Students should think independently and boldly explore the study activities based on the existing knowledge, combined with hands-on learning and vision for the future.

Thus, innovative learning emphasizes on the exploration of the unknown. Therefore, during the stage of postgraduate, graduate innovative learning is more than just the acquisition of knowledge through classroom study. It also emphasizes scientific research. Thus graduate, in addition to learning some lessons knowledge, the main thing is, under the guidance of instructors, to study on his own research deeply, and form research results. In this process, the abilities to exercise their scientific study, information acquisition, and innovation can be improved. Therefore, the innovative learning of graduate students is to gain knowledge and improve innovative capacity of learning under the guidance of the tutor by studying new topics and solving new problems, [1]. The characteristics of graduate innovative learning mainly show prospective, problematic, procedural and autonomy. 
The general process of graduate innovative learning includes selecting research direction, research topic, access to information, writing academic research papers and academic exchanges [2].

In the process of building higher educational great-powers, our graduate teaching has made considerable progress, with the formation of a unique graduate teaching mode of combining the mentoring graduate students and in-classroom teaching, but this mode lacks teaching practice and training, the loose connection of scientific study and reality demand, and the shortage of innovative power. In response to this situation, full-time professional training course is set for software engineering graduates, combined with engineering practice courses of software engineering. The authors explore the graduate innovative learning teaching mode, and achieve good results.

\section{The Exploration on Graduate Innovative Learning and Teaching Mode}

Graduate Engineering Teaching supported by "Excellent Engineer Training Program". In order to meet the demand of China's "Strengthening core competitiveness, and building an innovation-oriented country" for the ministry, "Excellent Engineers Training Plan" is a great innovation measure for completing the national goal of serving initially China's "Taking a new road to industrialization" and "going out strategy". The project has been listed in the national medium and long-term program for education reform and development, and has been highly valued. In June 2010, Nanchang University was approved by the Ministry of Education as one of the first batch of pilot colleges and universities. According to the actual teaching and combined with the teaching characteristics of Nanchang University School of Software, the preliminary pilot "Excellent Engineers Training Plan" of Nanchang University School explores to cultivate "practical" and "design" engineer in the stage of undergraduate and engineering master, using training patterns in stages.

The undergraduate stage gives priority to developing "Application Engineers", four years of schooling, and adopt the " $3+1 "$ mode, that is, spending 3 years at school on studying theoretical courses and practical courses, and spending 1 year learning in the enterprise and doing graduation project.

Master's stage mainly cultivates "Design Engineers", 2 years of full-time master of engineering, to adopt "1+1" model, spending 1 year for studying at school, and 1 year working and studying in the enterprise. Last year, focusing on cultivating students' practical ability, the final year of study in the enterprise will greatly increase students' practice in the enterprise. The purpose is to make students become interdisciplinary talents with moderate solid theory foundation, skilled practice ability, strong ability of problem analysis and problem solving, good interpersonal communication skills, following the norms, and being people with a sense of engineering.

In order to further strengthen the engineering teaching and highlight the school characteristics, NCUSS vigorously reforms mechanism, actively cooperates with enterprises in depth, establishes the model of university-enterprise cooperation in running schools. Both parties make joint personnel training scheme to build the practical bases, joint labs, and train the skilled talents together. Therefore, it provides the foundation and guarantee for reforming talents training mode and improving the quality of education. In recent years, NCUSS has signed cooperative agreements with Microsoft, IBM, Shanghai Kai Jie, Lakshya Company (India), Appin Company (India), Neusoft Group and other enterprises and institutions, so as to jointly establish practical bases and laboratories for training software talents together. It realizes the seamless link of college and enterprise, and 
provides good mechanism for jointly cultivating software talents, which enables the cultivated talents to meet the requirement of market demand and fit the social development [3].

Production, Study and Research Joint Training Centered on the Demand. Relying on Nanchang University, in 2001, Nanchang University National University Science Park was established with approval from Jiangxi provincial Department of Science and Technology and Department of Education. In 2004, National Ministry of Science and Technology, Ministry of Education jointly awarded it the title of "National University Science Park". It is an important high and new technology enterprise incubator, science and technology achievements transformation base, innovative entrepreneurial talent aggregation and training base, university-industry cooperation demonstration base and radiation base of high and new technology development in Jiangxi province.

To set up the graduate curriculum system of production, study and research joint training: Based on fully digesting and absorbing ordinary full-time graduate student curriculum system and attaching great importance to the advantages of basic theory, NCUSS strengthened the cooperation with universities and enterprises, and contacted the enterprise according to the actual demands. According to the requirements of enterprise technological innovation, NCUSS has developed a set of graduate curriculum system, which embodies the discipline frontier and practical production, study and research joint training and constantly improves the graduates' scientific research ability to solve practical technical problems.

To improve the enterprise graduate tutor system: Firstly, to establish enterprise tutor evaluation standard. the authors should establish a unified enterprise tutor appraisal committee, in order to define the enterprise admittance criterion and manage the good quality of tutors. Secondly, to build enterprise performance appraisal system, strengthen the performance assessment of enterprise tutors, develop the role of mentoring graduates, and prevent enterprise tutors from becoming "Front Mentors".

To form a good incentive and constraint system: To improve the graduate system of production, study and research, the first is the benefit-sharing mechanism, especially in the aspects of technology research and development, and personnel training, the authors should form a pattern of production, study and research win-win situation. The second is risk resolution mechanism. On the basis of the existing, in view of the characteristics of production, study and research joint cultivating mode, the authors should improve production, study and research cooperative agreement, to guard against and dissolve the cooperation risk. The third is the responsibility restraint mechanism, clear the responsibilities of the enterprise and school, establish strict regular examination evaluation system and improve the quality of the joint training study together [5].

Guided by the scientific research of graduate students innovative learning ability. Strengthen the scientific research training: Research project is an important means of training graduates to engage in scientific research ability, which is an important way to develop innovation spirit, improve analysis and problem-solving ability. Therefore, in teaching practice, the authors firmly grasp the main line of the subject research, strengthen the basic scientific research ability training of students, and improve their innovation ability and scientific research level. The specific way is, after the admission of graduates, and after confirming the mentors and students between each other, to elect the mentor and students into the project team, and the mentors and graduates will experience project from the project application, implementation, concluding the acceptance, and etc. During the process, a mentor should guide all the way, to regularly listen to the report on graduates' research progress, and find the problem and point it out. When graduates get certain scientific research experiences, the 
authors should encourage graduates to actively apply for the subject, and make them gradually have the ability of scientific research.

Strengthen professional internal communication: On the basis of fixing the mentors and research team, the authors break the boundaries of traditional mentors and research directions, by participating in different groups, organizing seminars and academic achievements communication meetings, strengthen the communication between the different research directions, and guide the communication between the academic achievement of graduates and inspire innovative consciousness and innovative thinking. Establish tutor guidance team and comprehensively guide graduates or graduates team through mentor group. Meanwhile, the authors should respect the student's individuality and interest, and teach them according to their aptitudes.

Deepen the social practice experience: Knowledge comes from practice, and practice is the only way which must be experienced by graduates while they are growing up. Only by taking into practice, understanding the current situation and demand of production and life can graduates shoot the arrow at the target, and carry out scientific research. Based on the reality that most graduates lack practice, by organizing visits, periodic practice, setting up a social investigation activity weeks, the graduates are led in the docking of the scientific research and reality, thinking deeply and solving practical problems, which is very helpful to improve the effectiveness and innovation of scientific research ${ }^{[2]}$.

\section{Conclusion}

After an innovative study of the teaching practice of for a period, the expected target and effect of the curriculum have been reached and some results have been gained. The teaching mode of innovative learning is an effective teaching mode to cultivate the innovative ability and innovative spirits of talents. In order to implement this teaching mode, schools, teachers and students shall promote each other. Only by constant exploration can researchers finally achieve success.

\section{Acknowledgement}

This paper is the phase research of JiangXi Degrees and Graduate Education Teaching Reform Project "Software Engineering Graduate Researching innovative learning model" (project number: JXYJG-2012-010)

\section{References}

[1] Huang Meifang, Graduates Innovative Study and Research, Higher Engineering Education Research, 2007(4)

[2]Yu Lianqing, An Attempt of Graduated Cultivation Mode Reform: Multi-faceted Experiential Research, Education and Professions 2013(24)

[3]Hu Jun, Excellent Engineers of Software Talents Training Plan and Exploration [J], 2011

International Conference on Education and Education Management, 2011

[4]Hu Jun, The Reform and Practice of Professional Software Talent Training Mode [J], 2011

International Conference on Education and Education Management, 2011 
[5]Cheng Aijie, The Patterns and problems of Production, Study and Research Joint Cultivating Graduates, Education Development Research 2008, 13-14

[6]Ji Yi, Chen Guoqing, The Teaching Research and Practice of Graduates Innovative Study, Computer Engineering and Science, 2011, 33 (zl)

[7]TAN Tao,Wang Yaming. Exploration and Practice of International Software Talents Cultivation, Computer Education, 2010

[8]Dai Yu,Zhang Bin, Exploration and Practice of Diverse Software talents Training Mode, Computer Education, 2009

[9]LIN Jian.The Development of General Standards for "a Plan for Education and Training Outstanding Engineering", Research in Higher Education of Engineering,No.4,2010

[10]SUN Xuan, ZHANG Boping. Exploration of Practical Teaching Model in Software Engineering Based on "Project-Tutorial System", Henan Education, June, 2009 